\title{
Impact of COVID-19 on college seniors' learning and performance in communication sciences and disorders: Students' self-reflections
}

Anthony Pak-Hin Kong

School of Communication Sciences and Disorders, University of Central Florida, Orlando, FL, USA

Purpose: A recent summary of ASHA surveys (fielded in March and April 2020) has delineated the pandemic-related challenges in education of communication sciences and disorders (CSD). This paper aimed to estimate how COVID-19 affected college seniors' learning and course performance, and discuss how a threat is posed to workforce entering.

Methods: Ninety-eight written reflections were analyzed using a descriptive analysis to determine how sudden termination of face-to-face instruction affected learning, and subsequently impacted seniors' completion of course assignments and test performance.

Results: It was found that students' loss of motivation, concentration, and/or self-discipline when adjusting and adapting to the pandemic posed the greatest challenge to knowledge acquisition and studying. Losing class engagement and face-to-face clinical exposure greatly hindered skill application; both elements lowered preparedness and satisfaction of college experience, and might reduce seniors' competitiveness and readiness to launch a new job.

Conclusions: As the coronavirus era is evolving, student comments and reflections become particularly valuable for gaining insights into improving online teaching and learning for future career.

Keywords: COVID-19, Student experience, Student reflection, Remote learning

\section{INTRODUCTION}

COronaVIrus Disease 2019 (or COVID-19) was named by the World Health Organization (WHO) on February 11, 2020 to refer to an infectious disease caused by a newly discovered coronavirus that has spread throughout the world. With WHO's later declaration of COVID-19 a pandemic on March 11, 2020 [1], many countries worldwide have decided to temporarily close educational institutions (i.e., schools, colleges, and universities). This was also the case for most universities in the nation, in which in the middle of the Spring 2020 semester before or following spring break, have made it mandatory to immediately move all academic teaching to a remote or online instructional format. A recent summary of American Speech-Language-Hearing Association (ASHA) surveys (fielded in March and April 2020; see full survey details and results in https://www.asha.org/Research/memberdata/COVID-19-Tracker-Survey/) has delineated the pandemic-related challenges in education of communication sciences and

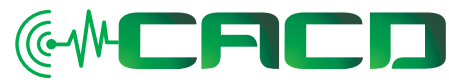

Received: October 29, 2020 Accepted: December 25, 2020

Correspondence:

Anthony Pak-Hin Kong

School of Communication Sciences and Disorders, University of Central Florida, Orlando, FL, USA

Tel: +1-407-823-4791

Fax: +1-407-823-4816

E-mail: antkong@ucf.edu

(C) 2020 The Korean Association of SpeechLanguage Pathologists

This is an Open Access article distributed under the terms of the Creative Commons Attribution NonCommercial License (https://creativecommons.org/ licenses/by-nc/4.0/) which permits unrestricted noncommercial use, distribution, and reproduction in any medium, provided the original work is properly cited. 
disorders (CSD) [2].

Most undergraduate degrees in CSD are centered around "the basic science of human communication including biological, physical, social, and linguistic aspects, and this basic science is used as a lens to develop understanding of what happens when communication is impaired" [3]. The majority of students pursuing the CSD major as a pre-requisite for working as a certified and licensed clinical speech-language pathologist (or audiologist) to assist individuals with communication difficulties caused by genetic, developmental, psychological, acquired neurological, or unknown conditions. While there have been scattered reports of how closures of various educational institutions are impacting students around the globe, the United Nations Educational, Scientific and Cultural Organization [4] has estimated that, as of April 2020 , over $91 \%$ of the world's enrolled learners across almost 200 countries have been negatively affected. The sudden switch to online education is in an unprecedented scale, with immediate short-term disruptions to most students' learning, productivity, and social life. On the part of both educators and students, some major sources of difficulties include the unprepared and unexpected moving to a pedagogical platform that is drastically different from the traditional face-to-face fashion, the need to trial-and-error that may reduce learning effectiveness, sudden changes to online assessments or cancellation of assessments, as well as a huge degree of uncertainty pertaining to the long-term consequences for the affected students.

Most, if not all, higher education institutions within and outside the United States have been impacted by the COVID-19 pandemic. Those who suffer immediately are students whose learning is impacted in various degrees by campus closures and subsequent shifting to remote teaching instruction. However, the journeys of students in higher education in this coronavirus era have yet been studied. In other words, there is very limited published research reporting the extent to which students comment on how they were influenced by the pandemic. This is also the case for educators who may feel unprepared to teach in an uncertain environment.

A recent article by Dhawan [5] has summarized the pros and cons of online teaching, reviewed various e-learning modes of education in the time of COVID-19 crisis, and highlighted the fact that remote learning is no longer an option but a necessity amidst this pandemic. Specifically, students typically benefit from online learning because of the flexibility in choosing the time and location to complete coursework and the immediate feedback they can receive in synchronous learning environment through teaching flatforms such as Zoom, Microsoft Teams, or Adobe Connect. In terms of opportunities, the switch to remote education could arguably improve students' problem-solving skills, critical thinking abilities, and adaptability; educators would also need to be creative to transform their pedagogical approaches and develop innovative and engaging methods to facilitate teaching [6]. On the other hand, some commonly reported weaknesses of remote learning include the lack of opportunities for social interactions and/or instructors' attention, limited access to equipment or insufficient technical support to facilitate optimal learning, students' diminished level of confidence and increased level of confusion, frustration, and anxiety, and disorganized learning process due to problematic time management or distractions [7]. These negative factors may pose further challenges on the part of the educators when it comes to ensuring the overall quality of education.

A small number of reports that specifically examined the differences of student performance in online versus face-toface undergraduate CSD courses have suggested the benefits and better student self-ratings of in-person teaching. For example, undergraduate CSD students enrolled in a face-to-face 'human anatomy and physiology' course were found to produce a significantly higher percentage of correct terms, in comparison to those enrolled in the online format, with a significantly higher self-rating of pronunciation ability [8]. Similar findings have also been reported by Saltarelli et al. [9] who indicated that undergraduate students in a face-to-face 'human anatomy' course performed significantly better in the identification and explanation of key anatomical structures on a human cadaver; this was in contrast to the poorer demonstration of cadaver-based knowledge and performance in learning tasks among students who were enrolled in the online section of the same course.

The aims of the present paper were therefore twofold: (1) to estimate how much the COVID-19 interruption had an effect on student learning and course performance, and (2) to discuss how the pandemic poses a threat to college seniors in the field of CSD to enter the workforce.

\section{METHODS}

An undergraduate course on multicultural aspects of communication disorders and differences in the School of Communication Sciences and Disorders at a large southern uni- 
versity was used to investigate students' reflections of how much the COVID-19 interruption had affected their learning and course performance. It is one of the 3-credit-hours core courses for students in senior standing, which focuses on the cultural and linguistic diversity among individuals with communication disorders and differences (with a special emphasis on African, Hispanic, Asian, and Native American). This School is one of the largest CSD programs in the nation with a current enrollment of approximately 750 bachelor's-level and 210 master's-level students.

A total of 101 CSD undergraduate seniors have enrolled in one of the two sections offered in Spring 2020. Both sections were setup as a mixed mode (i.e., reduced seat time) course that included required classroom attendance as well as online instruction. Classes had substantial activity conducted online, which substituted for some classroom meetings. In particular, for the 15 weeks in the original course setup, each student was required to attend weekly either a three-hour face-to-face meeting or a three-hour online module, depending on the topics and contents to be covered that varied across weeks. The same instructor was used across both offerings of the course. Typically, a face-to-face meeting included two or more mini-lectures by the instructor supplemented by class activities, group discussions, video review and/or assignments for application and knowledge consolidation. On the other hand, an online module typically included video review, teaching materials and online resources, assignments, and extended readings for self-paced learning.

As a result of COVID-19 in the Spring 2020 semester, after the ninth week of hybrid class meetings had completed, the remainder one-third of instructions (as well as remainder course assessments and final examinations) switched to a mandatory remote instructional mode. An end-semester written reflection paper, containing four questions, was added for students to detail their perception of this change:

1. Describe the top three impacts to learning overall (i.e., acquisition of knowledge at the university, including academic as well as clinical courses) resulting from the sudden termination of face-to-face instruction.

2. Describe the top three impacts to learning of content specific to the above-mentioned course (i.e., acquisition of knowledge in the course only) resulting from the sudden termination of face-to-face instruction.

3. Whether the sudden termination of face-to-face instruction affected students' completion of course assignments of the above-mentioned course? If so, why and how? If no, why?
4. Whether the sudden termination of face-to-face instruction affected students' performance in class quizzes and/or examinations of the above-mentioned course? If so, why and how? If no, why?

A total of 98 reflection papers returned, representing comments from about $13 \%$ of the total undergraduate student body in our program. A descriptive analysis following Kong $[10,11]$ was used to examine the students' perception. In particular, the content in all written reflections were analyzed using a content analysis modified from the descriptions in De Wever et al. [12]. Common words or phrases in the reflections were identified by one single rater, followed by grouping and coding of these written responses into consistent themes or ideas and, subsequently, tallying them. Each reflection was anonymized and randomly assigned a number from \#01 to \#98 before the content analysis was conducted.

\section{RESULTS}

Regarding the impacts to overall learning (i.e., acquisition of academic and/or clinical knowledge) resulting from the sudden termination of face-to-face instruction, the results of descriptive analyses revealed 14 themes of students' perceived negative effects (see Table 1). It should be noted that the positive comments about the spring 2020 experience were not nearly as plentiful as the negative ones. Examples of comments identified with illustrative quotations selected to each theme, in descending order of the percentage of total comments, are listed below:

1. Loss of motivation, concentration, and/or self-discipline to learn or study

- "My motivation diminished as I had to prepare my household and family to endure the repercussions of this pandemic." (\#28)

- "There is reason behind some classes not being online, simply because the method of in-person attendance outputs a greater result of learning than virtually. Through online instruction, students are more likely to lose motivation to log-in and attend class simply because it becomes more of an option." (\#49)

2. Increased personal responsibility to maintain academic changes, routines, and/or workload

- "I found that many professors began giving more weekly assignments than before remote learning began. This made it harder to organize all my assignments and complete them on time." (\#98) 
Table 1. Student Comments Pertaining to Overall Learning of Academic and Clinical Knowledge at the University Resulting from Sudden Termination of Faceto-face Instruction

\begin{tabular}{|c|c|c|}
\hline Theme & Number of comments & Percentage \\
\hline \multicolumn{3}{|l|}{ Negative Impacts } \\
\hline 1. Loss of motivation, concentration, and/or self-discipline to learn or study & $47 / 313$ & $15.02 \%$ \\
\hline 2. Increased personal responsibility to maintain academic changes, routines, and/or workload & $36 / 313$ & $11.50 \%$ \\
\hline 3. Loss of class engagement that benefits learning & $36 / 313$ & $11.50 \%$ \\
\hline 4. Loss of immediate and/or direct response from professors and need to teach oneself & $34 / 313$ & $10.86 \%$ \\
\hline 5. Total switch to online learning is not as effective and/or (mentally) exhausting, distracting, and/or stressful & $33 / 313$ & $10.54 \%$ \\
\hline 6. Learning hindered by home environment and/or duties & $33 / 313$ & $10.54 \%$ \\
\hline 7. Loss of face-to-face clinical exposure & $29 / 313$ & $9.27 \%$ \\
\hline 8. Loss of campus resources (i.e., study and/or technology support) & $18 / 313$ & $5.75 \%$ \\
\hline 9. Failure to retain as much of the information & $13 / 313$ & $4.15 \%$ \\
\hline 10. Missing opportunities to develop in-class rapport with professors and/or peers & $12 / 313$ & $3.83 \%$ \\
\hline 11. Loss of regular campus life & $9 / 313$ & $2.88 \%$ \\
\hline 12. Lack of social interactions outside of home & $4 / 313$ & $1.28 \%$ \\
\hline 13. Loss of face-to-face work experience on campus & $3 / 313$ & $0.96 \%$ \\
\hline 14. Loss of face-to-face research exposure & $2 / 313$ & $0.64 \%$ \\
\hline \multicolumn{3}{|l|}{ Positive Impacts } \\
\hline 1. Extra time or less distraction at home for completing class-related work & $2 / 313$ & $0.64 \%$ \\
\hline 2. Previous positive experience with online learning & $1 / 313$ & $0.32 \%$ \\
\hline 3. Reduced workload & $1 / 313$ & $0.32 \%$ \\
\hline
\end{tabular}

3. Loss of class engagement that benefits learning

- "Before COVID-19, I used to study in groups all the time. Working closely with friends and classmates really helped my understanding of specific subjects and overall performance. Now, we cannot have study dates. Yes, we can zoom each other but again, it is not the same." (\#93)

4. Loss of immediate and/or direct response from professors and need to teach oneself

- "Some professors have vague materials (i.e. PowerPoints, notes, word docs.) that were clearly meant to be paired with a lecture, that have not been elaborated, or edited for students to understand what the connections were." (\#29)

- "Zoom classes felt rushed and not as in-depth as faceto-face instruction." (\#78)

5. Total switch to online learning is not as effective and/or (mentally) exhausting, distracting, and/or stressful

- "While I've taken many online classes in the past, I have never had to take an entire semester online. Therefore, going from six in person classes to six online classes took a lot of adjustment." (\#36)
6. Learning hindered by home environment and/or duties

- "Having to move off campus and back to my family home has made taking tests, studying, and completing assignments infinitely harder. It's difficult to work when you don't have your own work space and people are constantly talking to you, checking on you, etc." (\#82)

7. Loss of face-to-face clinical exposure

- "I do feel that first and foremost certain clinical experiences were not available, taking away some valuable experiences." (\#23)

8. Loss of campus resources (i.e., study and/or technology support)

- "I would usually go to the library or study halls to study but because they are closed, I cannot." (\#34)

- "The most debilitating impact was the loss of resources provided by the college. I often used the printer stations and study areas around campus. Not being able to access these helpful resources created stress and a feeling of hopelessness." (\#73)

9. Failure to retain as much of the information

- "My acquisition of knowledge was greatly impacted in this process because I find myself to be an auditory/vi- 
sual learner. I can read an article and learn from it, but I will not retain the information as easily (or keep it as long) as I would if I was watching/listening to a lecture." (\#13)

10. Missing opportunities to develop in-class rapport with professors and/or peers

- "There is also a resounding feeling of being alone in my academic journey when all of my classes are online. I feel more crippled by my schoolwork because I have not been able to relate to anyone who is experiencing the same obstacles I am." (\#13)

- "I would have to reach out to my professor online, instead of at the end of class, for example, discouraging me a little before I did reach out with any questions" (\#69)

11. Loss of regular campus life

- "It is my graduating semester, so suddenly seeing everything fall apart and be cancelled was hard to process. Big milestones were just nonexistent anymore, such as birthdays, anniversaries and graduations." (\#02)

12. Lack of social interactions outside of home

- "Lack of social interaction outside of home, as well as the constant engagement in schoolwork due to the online format is mentally exhausting." (\#35)

- "Coming to campus was a form of escape for me, it was a part of my daily routine. It is so difficult being trapped in my apartment and learning over a computer. I love in person lectures and I love being social." (\#46)

13. Loss of face-to-face work experience on campus

- "It affected my job. I work on campus as a Resource Facilitator for Inclusive Education Services.” (\#03)

14. Loss of face-to-face research exposure

- "I was unable to present my research project at SURE (Showcase of Undergraduate Research Excellence)." (\#68)

Out of the total 313 pieces of comments, four of them (or $1.28 \%$ ) were positive comments listed by four students. These statements were mainly related to advantages perceived such as extra time or less distraction at home, reduced workload, and positive experience with online learning:

Concerning the impacts to learning of course-specific contents related to multicultural aspects of communication disorders and differences, the student respondents indicated nine major sources of negative effects resulting from the sudden termination of face-to-face instruction (see Table 2). Similar to the responses to the first question, there was a much higher proportion of negative comments. Selected illustrative quotations for each theme are listed below in descending order:

1. Loss of in-class activities and/or group work to consolidate learning

- "There is no longer the opportunity for in class discussions. I feel that this played a huge role this class as a whole and our learning experience based on the focus of this class. In-class discussions were beneficial and informative to each student on different cultural backgrounds and experiences, and helped each student to grow more culturally competent." (\#84)

2. Limited opportunities or more difficulties in grasping concepts and acquiring knowledge in the online platform - "With our face-2-face instruction being terminated, I do not feel as though I learned the content as well as I would've learned it in class." (\#91)

3. Loss of direct, first-hand, and/or immediate instruction and/or feedback from professor

- "Lectures from a professor greatly help me achieve this holistic comprehension. For me personally, listening to course material being taught is usually my main method of learning, while reading supplements it. Therefore, the ending of lectures made achieving comprehension of the course material more difficult." (\#53)

- "It is much harder to learn the class content without the direct guidance and encouragement of the professor or guided notes and PowerPoints." (\#76)

4. Loss of peer interactions and/or inputs

- "Talking after class, getting to know them outside of class and learning more about them, and hearing different viewpoints and perspectives really gave me insight into how important it is to value other cultures and learn more about them." (\#45)

5. Increased stress level with the change to taking quizzes online

- "When tests are moved onto an online format the ability to ask questions completely dissipates resulting in mistakes that could have been avoided." (\#73)

6. Loss of motivation and/or concentration to learn or study

- "I am not as motivated to really get into my readings when I am just at home. Usually I would complete my school work at Starbucks or the library. Now, I find myself getting distracted very easily at home so I definitely can't be learning as much." (\#93) 
Table 2. Student Comments Pertaining to Overall Learning of Course-specific Contents Resulting from Sudden Termination of Face-to-face Instruction

\begin{tabular}{|c|c|c|}
\hline Theme & Number of comments & Percentage \\
\hline \multicolumn{3}{|l|}{ Negative Impacts } \\
\hline 1. Loss of in-class activities and/or group work to consolidate learning & $66 / 296$ & $22.30 \%$ \\
\hline 2. Limited opportunities or more difficulties in grasping concepts and acquiring knowledge in the online platform & $64 / 296$ & $21.62 \%$ \\
\hline 3. Loss of direct, first-hand, and/or immediate instruction and/or feedback from professor & $53 / 296$ & $17.91 \%$ \\
\hline 4. Loss of peer interactions and/or inputs & $31 / 296$ & $10.47 \%$ \\
\hline 5. Increased stress level with the change to taking quizzes online & $27 / 296$ & $9.12 \%$ \\
\hline 6. Loss of motivation and/or concentration to learn or study & $20 / 296$ & $6.76 \%$ \\
\hline 7. Increased amount of time to fulfill course expectations & $16 / 296$ & $5.41 \%$ \\
\hline 8. Loss of campus resources (i.e., study and/or technology support) & $10 / 296$ & $3.38 \%$ \\
\hline 9. Mis-match of online materials and course assignments & $3 / 296$ & $1.01 \%$ \\
\hline \multicolumn{3}{|l|}{ Positive Impacts } \\
\hline 1. Professor's availability and willingness to help & $2 / 296$ & $0.68 \%$ \\
\hline 2. Extra time or less distraction at home for completing class-related work & $2 / 296$ & $0.68 \%$ \\
\hline 3. Class materials on online platform is well prepared by professor & $2 / 296$ & $0.68 \%$ \\
\hline
\end{tabular}

7. Increased amount of time to fulfill course expectations

- "I read the textbook very slowly for about six hours to prepare for the quizzes and felt that I still did not perform that well." (\#14)

8. Loss of campus resources (i.e., study and/or technology support)

- "Not being able to check-out and read the textbook located in the library." (\#63)

9. Mis-match of online materials and course assignments

- "The assignments given by the professor doesn't relate at all with the material that comes in the quizzes." (\#22)

Similarly, the descriptive analyses identified a small proportion of positive effects that were perceived by students. In particular, six out of the total 296 comments $(2.04 \%)$ were related to the following themes:

- Professor's availability and willingness to help

- Extra time or less distraction at home for completing class-related work

- Class materials on online platform is well prepared by professor

In regards to whether and how the sudden switch to remote instruction affected students' completion of course assignments, results of descriptive analyses yielded a total of 230 comments, including 137 negative and 93 positive ones. Interestingly, among the 98 students, 38 (38.8\%) of them mentioned exclusively the hindering effects, and another 32 (32.7\%) did not report any problems with finishing the coursework at all. The remaining 28 students (28.6\%) expressed a mix of pres- ence and absence of difficulties with various reasons. Table 3 summarizes the seven negative and another seven positive themes identified, which are listed below in descending order with illustrative quotations selected to each theme.

Negative effects to coursework completion included:

1. Increased amount of time to complete assignments due to less direct or structured instructions

- "It was definitely more of challenge to actually sit down on my own time, and complete the assignments." (\#74)

- "Prior to the switch, I had never missed an assignment. It wasn't until last week that I completely forgot to submit an assignment." (\#93)

2. Increased amount of stress and/or loss of directions that affects student motivation to complete assignments

- "It was such a drastic and quick change. This change had brought on an alarming amount of stress." (\#05)

- "For the last few assignments, I had a difficult time studying and was going through a particularly rough spot due to the quarantine. Gaining the motivation to work on the coursework was hard for me, but I got through it." (\#16)

3. Procrastination when completing assignments

- "I procrastinated more than usual with studying and submitting assignments" (\#71)

4. Loss of immediate or face-to-face feedback from professor

- "My knowledge in the course is primarily from the notes rather than from someone who has personally experienced it" (\#01) 
Table 3. Student Comments Pertaining to Completion of Course Assignments

\begin{tabular}{llc}
\hline Theme & Number of comments & Percentage \\
\hline Negative Impacts & $31 / 230$ \\
1. Increased amount of time to complete assignments due to less direct or structured instructions & $27 / 230$ & $13.48 \%$ \\
2. Increased amount of stress and/or loss of directions that affects student motivation to complete assignments $29 / 2.61 \%$ & $11.74 \%$ \\
3. Procrastination when completing assignments & $18 / 230$ & $7.83 \%$ \\
4. Loss of immediate or face-to-face feedback from professor & $15 / 230$ & $6.52 \%$ \\
5. Increased distraction from home environment, home and/or personal duties & $9 / 230$ & $3.91 \%$ \\
6. Loss of opportunities to work collaboratively with peers & $8 / 230$ \\
7. Loss of campus resources to complete assignments & $24 / 230$ \\
Positive Impacts & $21 / 230$ \\
1. Effective time management skills to complete assignments & $20 / 230$ \\
2. Clear and structured course setup facilitates completion & $8 / 230$ \\
3. Prior or existing experience with online learning & $8 / 230$ \\
4. Fair assignments designed or modified by professor & $7 / 230$ \\
5. Assistance from professor & $5 / 230$ \\
6. Additional time at home to complete assignments & $10.43 \%$ \\
7. Effective online platform to access and complete assignments & $9.13 \%$ \\
\hline
\end{tabular}

5. Increased distraction from home environment, home and/or personal duties

- "With all that is going on here back home, it has been hard with taking care of family, still work remotely, and keeping up with due dates." (\#03)

6. Loss of opportunities to work collaboratively with peers

- "The topics were more comprehensively covered and explained when sitting in a class with the teacher explaining a power point, and then being able to discuss the topics with my class mates." (\#44)

7. Loss of campus resources to complete assignments

- "(The University used to) offer many various resources to help students perform at their best and I definitely took advantage of what this University offers." (\#45)

- "Not being able to have access to the school's Internet forced me to have to savage for Wi-Fi in places that didn't allow you to dine in. It was tough." (\#55)

The lack of problems in finishing coursework was due to the following positive factors:

1. Effective time management skills to complete assignments

- "I am a very organized student and I plan my weeks ahead of time." (\#90)

2. Clear and structured course setup facilitates completion

- "I already knew the expectations for the online assignments and the fact that (the professor) made every as- signment with ample instruction was just a plus. The assignments followed the syllabus almost exactly so there was not a lot of need to re-arrange anything." (\#66)

3. Prior or existing experience with online learning

- "My experience with this course and the transition to remote learning has been mostly positive given that this is a hybrid course and I was already accustomed to the online format for this class." (\#35)

4. Fair assignments designed or modified by professor

- "I found the assignments when this happened to be easy and straight to the point and followed the module content very well." (\#96)

5. Assistance from professor

- "Students still had the option of emailing the professor if further clarification was needed on certain topics discussed in the online modules." (\#91)

6. Additional time at home to complete assignments

- "I have had more time to complete all of my essay assignments and weekly readings. Therefore, I feel less pressure overall because I have more time to write and then proofread my answers." (\#35)

7. Effective online platform to access and complete assignments

- "The instructions of all the assignments were clear, and (the professor) posted an updated announcement 
Table 4. Student Comments Pertaining to Performance in Class Quizzes and/or Examinations

\begin{tabular}{|c|c|c|}
\hline Theme & Number of comments & Percentage \\
\hline \multicolumn{3}{|l|}{ Negative Impacts } \\
\hline 1. Overall quality of learning is diminished or negatively affected & $48 / 224$ & $21.43 \%$ \\
\hline 2. Online platform of examination is less favored, distracting, and/or stressful & $42 / 224$ & $18.75 \%$ \\
\hline 3. Transfer from learning to examination is difficult & $37 / 224$ & $16.52 \%$ \\
\hline 4. Home and/or virtual environment is distracting for effective studying & $20 / 224$ & $8.93 \%$ \\
\hline 5. Loss of motivation and/or concentration to learn or study & $16 / 224$ & $7.14 \%$ \\
\hline 6. Decreased opportunities of quiz review and/or practice & $16 / 224$ & $7.14 \%$ \\
\hline 7. Lack of immediate clarification from professor when taking a quiz & $15 / 224$ & $6.70 \%$ \\
\hline 8. Loss of campus resources (i.e., study and/or technology support) & $10 / 224$ & $4.46 \%$ \\
\hline \multicolumn{3}{|l|}{ Positive Impacts } \\
\hline 1. Clear and structured quiz setup facilitates completion & $8 / 224$ & $3.57 \%$ \\
\hline 2. Keeping self-accountable to learning & $6 / 224$ & $2.68 \%$ \\
\hline 3. Time to study is sufficient & $4 / 224$ & $1.79 \%$ \\
\hline 4. Decreased level of stress or worry to take quizzes at home & $2 / 224$ & $0.89 \%$ \\
\hline
\end{tabular}

every week so I was never confused about new expectations." (\#50) (Table 3)

Finally, in terms of the effect of remote instruction on students' performance in class quizzes and/or examinations, descriptive analyses identified a total of 224 comments, with the vast majority of them being negative (204) encompassing eight themes (see Table 4). Over 83\% (i.e., 82 of 98 students) reported negatively on the impact on their test performance, and over $12 \%$ of students expressed both presence and absence of difficulties. Below listed examples of comments identified, with illustrative quotations:

Negative effects on test performance:

1. Overall quality of learning is diminished or negatively affected

- "Not having a face to face class, hurt my understanding of the material. I am very much so, an auditory learner, so when I had to read all the material on my own, I found it more challenging." (\#74)

- "Without being able to discuss in class the topics in more depth or how to relate them to real life scenarios it made it harder to answer questions on examinations that were more "apply the knowledge" type questions." (\#83)

2. Online platform of examination is less favored, distracting, and/or stressful

- "I may speak for many other students also when I say that taking quizzes or tests in-class is not as stressful as doing so online." (\#49)
3. Transfer from learning to examination is difficult

- "I feel like I did not get the same comprehensive learning of lessons, and that effected how well I carried over the information for quizzes and exams." (\#44)

4. Home and/or virtual environment is distracting for effective studying

- "I also believe that my environment dictated how much information I was taking in. When studying at home, there were so many distractions versus the controlled classroom setting." (\#92)

5. Loss of motivation and/or concentration to learn or study - "I found it challenging to gather motivation because of anxiety related to the quarantine." (\#17)

6. Decreased opportunities of quiz review and/or practice

- "There also was not a lot of study guides or review sessions held like there normally would be in a face-toface lecture." (\#21)

7. Lack of immediate clarification from professor when taking a quiz

- "If I had a question during the quiz or exam, I could come up to you in the classroom. With online testing we can't reach out to you during quiz or exam." (\#57)

8. Loss of campus resources (i.e., study and/or technology support)

- "The lack of resources has made it difficult for me to properly study for quizzes and know what information will be on the quizzes." (\#34)

Absence of any perceived impact on quizzes and/or examina- 
tions was due to the following positive factors:

1. Clear and structured quiz setup facilitates completion

- "Most quizzes were already on the online Webcourses platform and were routinely scheduled. The information necessary for each quiz was already clearly stated in the class itinerary from the beginning and we were all reminded at least a day or two by email beforehand." (\#4)

2. Keeping self-accountable to learning

- "How I do is based on how I adapt to the changes and reached out for help if it was difficult to learn from the new mode of class." (\#69)

3. Time to study is sufficient

- "While being stuck at home I have had a lot of down time to be able to spread out my studying then I would when we have face to face. Before the world was shut down I had extracurricular activities, work and school and I feel sometimes it's hard to manage things and unfortunately sometimes I don't get to study enough. My only focus right now is school." (\#37)

4. Decreased level of stress or worry to take quizzes at home

- "I have found that the comfort of my own home has decreased the worry I get when taking tests." (\#33)

\section{DISCUSSION}

Students and professors in CSD are being impacted extensively as a result of the quarantines and social distancing imposed to attempt to flatten the curve and lower hospitalizations and mortality rates. In order to best serve them in the coming academic semesters, especially in the era of this evolving pandemic, it is imperative for professors to understand how COVID-19 has influenced CSD students.

Although lectures and learning were no longer confined to the classroom environment, our results revealed a concerning impact of COVID-19 on education disruption and psychosocial wellbeing among prospective senior college graduates. First, as shown in Tables 1 and 2, students have exhibited signs of setback as a result of the withdrawal of formal instruction for about two months. Gradual loss of motivation, concentration, and/or self-discipline to learn or study among students, some of which overlapped with the psychological impact of COVID-19 reported in Brooks et al. [13], was alarming and could directly limit their opportunities for determination and success. Part of these negative experiences could also be induced by, in an accumulating manner, the combination of sudden transition to heavy use of video lectures/conferences and social isolation in circumstances such as lockdown or quarantine. It is fair to argue that higher education has been revolutionized by technology, but there are increasing number of reports regarding "Zoom fatigue" contributing to extra stressors (e.g., being conscious of how to behave properly in front of a camera, obligation to be performative in group chats, or being highly aware of being watched) when one works from home; such an effect is consistent with our students' reflections in the context of learning or test environments.

The study of CSD emphasizes on the bridging of didactic learning and experiential activities (including clinical observations and hours as well as externship or internship opportunities) for students to acquire foundational skills necessary for success in their future career. Another important implication of our finding, as displayed in Table 1, is the high proportion of students perceiving a significant ineffective content or knowledge acquisition (in terms of the direct teaching from course instructors and loss of class engagement that benefits learning) and missing of face-to-face clinical exposure or inperson practicum. In what degree this lowered preparedness and satisfaction of college experience may reduce college seniors' competitiveness and readiness to launch their careers remains an unknown. In this regard, a larger-scale investigation in the midst of an evolving pandemic is warranted.

A clear implication reflected by the findings in Tables 3 and 4 was the extra efforts necessary to connect the acquisition of course materials and building of clinical competencies through effective online learning experiences. It is reasonable to expect this growing need from students (nationwide and worldwide) in the coming semesters. Use of interactive learning packages, that feature dynamic activities such as role play scenarios, videos showing application of course principles in different CSD-related professions, and exercises in health communication, as a supplement to face-to-face lectures and textbooks may be one solution. Again, it is argued here that expanding the scope of this study to other (clinical and nonclinical) disciplines will be beneficial for a more holistic understanding on strategies to enhance student success and entering to a work place.

Most prospective graduates in their senior year, such as the majority of the students in this study who were in their final or second-to-last semester at college, begin searching and applying for jobs. In the pre-pandemic era, many students with an undergraduate degree in CSD started out in support posi- 
tions typically filled as vacancies occur year-round. In particular, many in-field graduates start an entry-level career in health and human services (e.g., speech and language assistants, hearing aid technicians/assistants, physician assistants, support specialists in long-term care facilities, medical administrative assistants in allied health sciences such as physical or occupational therapy) or in the field of education or psychology (such as assistants in schools, special education, or early childhood education). However, the current economic uncertainty (and potentially the subsequent recession) caused by COVID-19 is likely to post a threat to many graduates in securing a position in the workforce. Since the questions which were asked of the students in the present study were limited to their own learning experiences and were not directed towards exploring the issue of employment, one possible extension of this investigation is to examine how actions taken as a result of the pandemic impacted learning and academic performance; and to explore how these actions impacted college seniors' transition to the workforce.

Student reflections of their learning experiences can be important and useful information supplementary to student evaluation of teaching effectiveness routinely collected in universities. Student satisfaction has also been reported as a critical motivational factor for students as learners [14]. The COVID-19 pandemic has brought great challenges to the world. Its utter disruption and impact on education is not limited to specific disciplines, student backgrounds, ages, genders, or socio-economic status. In the coronavirus era, comments and reflections from students become particularly valuable for educators and institutional leaders to gain insights into improving online teaching and learning, both of which will raise the competitiveness for college seniors to gain a place in the workforce.

\section{DECLARATIONS}

\section{Funding}

The author did not receive any financial support for the research, authorship, and publication of this article.

\section{Conflicts of interest/Competing interests}

The author declares no conflict of interest.

\section{Ethics approval}

This paper relied on secondary analysis of anonymized data of student reflections in 2020. The data collection was not subjected to ethical review.

\section{REFERENCES}

1. World Health Organization. WHO Director-General's opening remarks at the media briefing on COVID-19 - 11 March 2020. https:// www.who.int/dg/speeches/detail/who-director-general-s-opening-remarks-at-the-media-briefing-on-covid-19---11-march-2020 Accessed 11 March 2020.

2. Volkers, N. What COVID-19 teaches about online learning. https:// leader.pubs.asha.org/do/10.1044/leader.FTR1. 25062020.46/full/ Accessed 16 Jun 2020.

3. American Speech-Language-Hearing Association. (n.d.). The value of the undergraduate degree in Communication Sciences and Disorders (CSD). https://www.asha.org/academic/value-of-theundergraduate-degree-in-csd/ Accessed 17 April 2020.

4. UNESCO. (n.d.). COVID-19 educational disruption and response. https://en.unesco.org/covid19/educationresponse Accessed 17 April 2020.

5. Dhawan S. Online learning: A panacea in the time of COVID-19 crisis. Journal of Educational Technology Systems. 2020;49:5-22.

6. Favale T, Soro F, Trevisan M, Drago I, Mellia M. Campus traffic and e-learning during COVID-19 pandemic. Computer Networks. 2020;176:107290.

7. Parkes M, Stein S, Reading C. Student preparedness for university e-learning environments. The Internet and Higher Education, 2014;25:1-10.

8. Cralidis AL, Salley SW. A comparison of Face-to-Face versus online instruction in the correct pronunciation of anatomical terms in communication sciences and disorders: An initial investigation. Teaching and Learning in Communication Sciences \& Disorders. 2020;4:Article 6.

9. Saltarelli AJ, Roseth CJ, Saltarelli WA. Human cadavers vs. multimedia simulation: A study of student learning in anatomy. Anatomical Sciences Education. 2014;7:331-339.

10. Kong APH. Students' perceptions of using Problem Based Learning (PBL) in teaching cognitive communicative disorders. Clinical Linguistics and Phonetics. 2014;28:60-71.

11. Kong APH. Using service-learning activities to enhance teaching of cognitive-communicative disorders: A case illustration in the discipline of communication sciences and disorders with reflections from student clinicians and community agencies. In S.-I. Hou (Ed.), Service-learning: Perspectives, goals, and outcomes (pp. 69-92). Hauppauge, NY: Nova Science Publishers, Inc. 2017.

12. De Wever B, Schellens T, Valcke M, Van Keer H. Content analysis schemes to analyze transcripts of online asynchronous discussion groups: A review. Computers and Education. 2006;46:6-28.

13. Brooks SK, Webster RK, Smith LE, Woodland L, Wessely S, Greenberg N, Rubin GJ. The psychological impact of quarantine and how to reduce it: Rapid review of the evidence. Lancet. 2020;395: 912-920.

14. Griffioen DME, Doppenberg JJ, Oostdam RJ. Are more able students in higher education less easy to satisfy? Higher Education. 2018;75:891-907. 